\title{
Automatic Operation of Naphtha Cracking Furnace by Optimizing Controller ${ }^{*}$
}

\author{
Toru Sogawa*, Shinpei Gomi***, Seiichi Miyazaki**** \\ and Kazuyuki Shiga**
}

\begin{abstract}
Summary: The authors have developed an independent process of manufacturing acetylene and ethylene through cracking naphtha, in their association with the Research Association of Polymer Raw Materials which is jointly participated in by 23 leading Japanese firms in the field such as petroleum, chemical, iron \& steel, etc.

In this process development, the thermal cracking furnace uas operated under control of optimizing controller ( $O P C O N$ ) achieving promising results even though on a pilot plant basis, an outline of which will be reported in this paper.

The naphtha cracking furnace used in this test was of an internal combustion type, and the process is that naphtha preheated at temperature of 500 deg. centigrade is injected into the combustion gas, containing steam, at high temperature.
\end{abstract}

The optimizing controller (OPCON) used in this test was of trial-and-error method type, manufactured by Mitsubishi Electric Company, allowing for six input and two output variables.

Oxygen and fuel gas flow quantities were selected as the output variables in this experiment. This OPCON is especially effective in selecting optimum operating conditions from alternatives in a short time, and it is also effective in searching for the condition at a broad step, or in case where the process control is made under many outside disturbances.

Even though it may be necessary to further investigate on such problems as the step in the output factor under minor outside disturbance, the authors could have in prospect an easy automatic control of this naphtha cracking process as applied in a commercial plant by utilizing a controlling instrument such as this.

In reviewing the operation carried out under OPCON control, the operating condition

* Received November 9, 1962.

** The Research Association of Polymer Raw Materials. Chiyoda Chemical Engineering and Construction Company. 188-1, Hairyochi, Ikegamishinden, Kawasaki, Kanagawa Pref. Japan.

*** The Research Association of Polymer Raw Mrterials. Kureha Petrochemical Company.

**** Chiyoda Chemical Engineering and Construction Company. has been settled at a combustion condition whereby the fuel was in excess of the theoretical quantity in every case, with excellent results of higher yield and less requirements of materials and utilities as compared to the case manually operated. The comparison of this process with one by manual control also reveals that the process is characterized by its relative stability in operating conditions.

\section{Introduction}

There have been various processes already reported on the acetylene and ethylene manufacture by cracking naphtha ${ }^{1,2,3)}$. Starting from the fundamental research work and the bench scale experiment since 1957, the authors have developed special pilot plants scaled at $0.5,3$ and 6 tons of acetylene per day, obtaining acetylene and ethylene simultaneously from petroleum fraction at high yield, and with the acetylene/ethylene ratio under control over a wide range.

In this paper, authors wish to report on the promissing results obtained from the pilot plant studies. Particularly, the optimizing controller (OPCON) was applied to the operation of the thermal cracking section, so as to establish the optimum operating condition and also to investigate on the adaptability of OPCON to this process. A special emphasis was placed on the characteristics of the OPCON and on the merit for 
utilizing the OPCON.

\section{Apparatus and Method of the Experiment}

\section{Outline of the Thermal Cracking Section}

The thermal cracking furnaces used in this experiment were of nominal capacities at 6 tons and 2 tons of acetylene per day. Fig. 1 shows a simplified flow sheet of the thermal cracking section. The fuel gas is burnt with

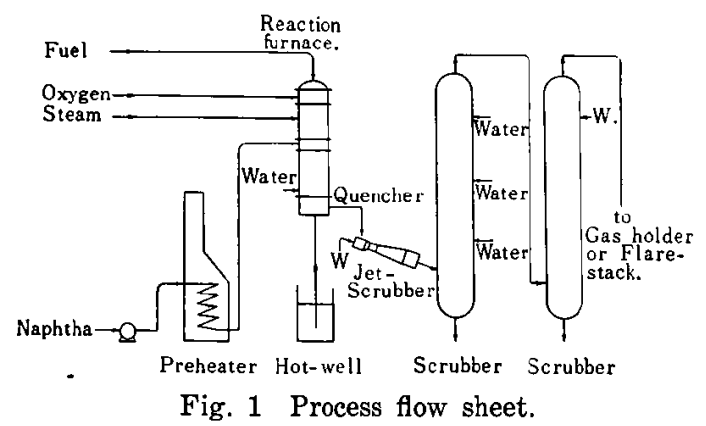

oxygen under presence of steam, then naphtha preheated at $500 \mathrm{deg}$. centrigrade is injected into the combustion gas at high temperature (more than 2,000 deg. centigrade), thereby cracking naphtha. Steam acts as a controller of the combustion temperature and also as a preventer of carbon formation. The gas coming out from the furnace is immediately cooled by quencher. Then the gas is passed through jet scrubber and then water scrubbing tower for cooling off, and at the same time, for removal of carbon and tar. The gas is disposed of at the flare-stack after measuring its total volume. The gas after water washing, is analyzed for composition by process gas chromatograph in every five minutes. For logging the data, five sets of gas chromatograph were used to analyze all gas components.

Light naphtha was used in this experiment as a feedstock and its characteristics are shown in Table 1. Waste gas was used as fuel gas. Liquified oxygen was used after evaporation.

\section{OPCON and its Instrumentation}

\section{Outline}

"OPCON"4) developed by Mitusbishi Electric Company was used as the optimum control instrument. There are various types and methods of optimum control. In this OPCON, a trial-and-error method ${ }^{5)}$ was adopted, and the outline is as follows: For a certain process which is subject to optimum
Table 1. Characteristics of the naphtha

\begin{tabular}{c|c|c}
\hline Specific gravity & $\mathrm{D}_{4}^{1.5}$ & 0.6692 \\
Distillation characteristic: & & \\
I.B.P. & deg. C & 37 \\
10\% pt. & deg. C & 49 \\
$50 \%$ pt. & deg. C & 61 \\
$90 \%$ pt. & deg. C & 89 \\
$95 \%$ pt. & deg. C & 98 \\
E.P. & deg. C & 113 \\
Recovery & vol. \% & 98.0 \\
\hline Group analysis: & & \\
Aromatic H.C. & vol. \% & 1.5 \\
Unsaturated H.C. & vol. \% & 0.6 \\
Saturated H.C. & vol. \% & 97.9 \\
Elementary analysis: & & \\
Carbon & wt. \% & 83.8 \\
Hydrogen & wt. \% & 15.8 \\
Sulfur & wt. \% & 0.02 \\
\hline
\end{tabular}

control, there must be a certain process value to be set at an optimum, and the optimum control is to either minimize or maximize this value. This value may be measured as a direct process variable in some cases. However, it is usually calculated from several process variables. Among these process values are the yield (the optimum means the maximum in this case) and the cost (in this case the optimum means the minimum). Such functions as these to be set at optimum are called the objective functions. It follows that, therefore, some of process variable are changed in order to either maximize or minimize the objective function. With the trialand-error method, the maximum or minimum objective function is sought by the following procedures.

In the first place, the process plant in question is operated under a certain condition, and an objective function corresponding to the condition (at a steady state) is computed, and this value is to be remembered by the computor. Then, the process variable is changed and the subsequent objective function is computed under new condition (at a steady state). Upon comparison of the new value against the remembered value, if the new value is greater than remembered, the latter operation, or the trial operation, is judged as a success (in case the maximum is required).

On the other hand, a smaller value in the trial is to be judged as a failure. Subsequent trials are made in the same manner. 
The second trial, if the first trial was a success, must be made in the same direction as the first. In case of first one was a failure, the second trial must be in the opposite direction. By repeating such trials, a maximum point of the objective function, namely, the optimum point will be achieved. After reaching this point, all other trials made for any direction will fail. This point is thus judged as the maximum.

The optimizing controller is a device adopting trial-and-error method in which the above trial and the judgment of the result of the trial is automatically carried out. The Mitsubishi Electric Company's OPCON has an electronic computor section of analog type and the objective function is computed from the process variables measured in this computor section.

The objective function calculated by the electronic computor of analog type is remembered in a digital form by means of AC-DC converter. In the OPCON used, there were two operating variables, and there are eight directions for trial by combination of operations, increasing or decreasing the two variables. There is a control sectoin in the OPCON which makes judgment on success or failure, and based on this judgment further trial is made upon selection of the trial direction according to a certain definite logic. OPCON includes all of the above devices, from input of the process variables up to the ouput. Fig. 2 shows instrumentation

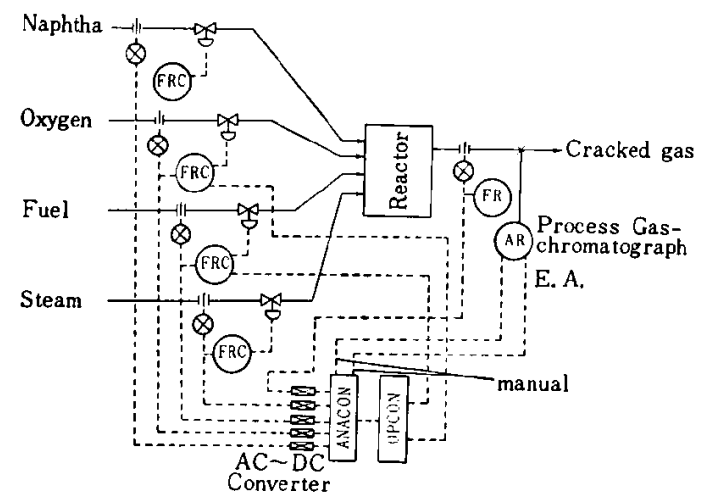

Fig. 2 Instrumentation diagram

in connection with OPCON. Every flow quantity detected is supplied to the controller or recorder in a converted form of A.C. current ranging from 0 to $0.5 \mathrm{~V}$ by the transmitter. On the other hand, this signal is branched and is supplied to the analog computor through $\mathrm{AC}$ to $\mathrm{DC}$ converter, in a form of $\mathrm{DC}$ current ranging 0 to $50 \mathrm{~V}$.
Process gas chromatograph was used for the gas analysis. As this gas chromatograph did not have an output mechanism, a manual setting was adopted by setting the potentiometer of the analog computor by hand, after measuring the recorded bar-graph on the paper. Since the output of the OPCON is indicated on the potentiometer, the $\mathrm{AC}$ output ranging 0 to $0.5 \mathrm{~V}$ was supplied as the index signal of the controller by adding $0.5 \mathrm{~V}$ of $\mathrm{AC}$ source to the potentiometer.

The objective function of the OPCON was selected for maximum profit, which is computed by analog computor, and the profit equation is as follows:

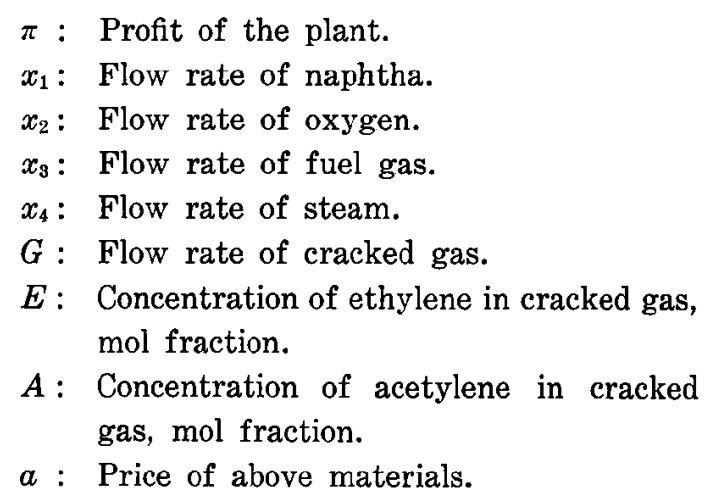

Each flow rate was input into analog computor as the percent of the flow indication of the instruments.

$$
\begin{aligned}
\pi & =a_{1} G(E+A)+a_{2} G(1-E-A) \\
& -a_{3} x_{1}-a_{4} x_{2}-a_{5} x_{3}-a_{6} x_{4} \quad \ldots
\end{aligned}
$$

As the output variables of the OPCON, flow rates of oxygen and fuel gas ( $x_{2}$ and $x_{3}$ ) were selected, because these variables govern the reaction to a great extent.

\section{Restriction with OPCON}

1) Flow of Oxygen and Fuel: The maximum flow is to be decided from the plant capacity, and the minimum is to be decided according to the limitation for maintaining the steady combustion. Especially, the maximum flow will be related to the rate of steam consumption. However, it will be limited by the maximum temperature at which the refractory of the combustion chamber causes fusion trouble. The ratio of flow of fuel to oxygen wil be also limited by the maintenance of steady combustion.

2) Limitation of Cracked Gas, Related to the Subsequent Process Stage: Acetylene and ethylene are the main products aimed at this process plant. Accordingly, the greatest yield of the total of the two 
products $(\mathrm{E}+\mathrm{A})$ is desirable. However, the increased total yield alone is not enough to programme the subsequent process stage. It is believed that the ethylene to acetylene ratio must be within a certain range and any other ratio off this range results in a loss. Let the optimum ratio of ethylene to acetylene be $\gamma$ and the loss is estimated as follows :

$$
a_{7} G|E-\gamma A|
$$

This loss should be deducted from the equation (1) which give the plant profit:

$$
\begin{aligned}
\pi & =a_{1} G(E+A)+a_{2} G(1-E-A) \\
& -a_{3} x_{1}-a_{4} x_{2}-a_{5} x_{3}-a_{6} x_{4}-a_{7} G|E-\gamma A| \ldots(2)
\end{aligned}
$$

In the experiment, the above equation (2) was used to obtain the maximum profit into which the limited ethylene/acetylene ratio was introduced. The calculation is made by analog computor. According to the results obtained heretofore, when the restriction on ethylene/acetylen ratio is not introduced, it was anticipated that the point of maximum profit will move toward the ratio in which ethylene is rich, off the minimum restricted condition of the oxygen and the fuel. On the other hand, with addition of the restriction condition of ethylene/acetylene ratio, it was expected that the point of maximum profit will come into the restricted range conditioned by equations (1) and (2), and that there is only one point.

From this view, it was presumed that the optimum point will not go beyond the restricted condition unless there occurs trouble, and in case of emergency if it comes out of the restricted condition, the detection was so scheduled as to be made by manual because of this being a pilot test. As for the restriction (1), a special caution was given to the maximum value, and also to the ratio of each flow so that the combustion temperature does not exceed 2,800 deg. centigrade under the assumption that the fuel is perfectly burnt in the furnace. For the restriction (2), the ratio of ethylene/acetylene was 1.0 for the Experiments 1 thru 4, and 1.1 for Experiments 5 and 6.

\section{Result of the Experiment}

As the operation by OPCON was carried out as one of a series of tests, like those for other purposes, with the loop closed, it was impossible to obtain experimental data for a long period of time.

One experiment took approximately four to eight hours. The experiments were carried out as follows:

(EXPERIMENT-1) This experiment was carried out to search for an optimum condition: OPCON loop was closed taking the condition of the previous operation as a reference for searching for the optimum condition.

(EXPERIMENT-2 and 3) In this experiment the maximum point was purposely moved by changing process-parameter: Steam flow was chosen as a parameter. Two different steam flows were used to search for the optimum point.

(EXPERIMENT-4) This experiment was to check the reproducibility of OPCON in search for the optimum point. After OPCON found an optimum point, the experimental conditions were changed. The experiment was started once again with the output variables except oxygen and fuel set at the same condition as before to find the optimum point.

(EXPERIMENT-5 and 6) These experiments analyzed advantages of utilizing the OPCON: Two alternate cases were compared for plant operation profit: one by OPCON against another by manual control. In case of OPCON, the operation was held at the optimum point, while the latter maintained by manual after breaking the OPCON loop at the optimum condition, OPCON had search out.

Experiments 1 thru 4 were carried out in a 6-ton-per-day furnace, while 5 and 6 in a 2-ton-per-day furnace, both on an acetylene production basis. Oxygen and fuel flow as percent range of the flow indicators were plotted against time in Fig. 3 (for Experiment-1 to 4) and Fig. 4 (for Experiment-5 and 6) shows a plot of plant operation profit contrasted to oxygen and fuel flow rates. The plant operation profit is computed by ANACON according to the equation (2) whereby yield of $C_{2}$ fraction, ethylene/acetylene ratio and change in various flow quantities are all reflected. Table 2 shows the conditions at the beginning of OPCON operation, and the final experimental conditions and the result OPCON searched out. In this experiment, only the steam rate was changed as a parameter of the process. However, there can be other parameters such as fuel, oxygen, naphtha, and pressure, and there must be optimum conditions corresponding to each. Therefore, the optimum condition obtained from OPCON in this experiment 
Table 2. Comparisons of the operated results

\begin{tabular}{|c|c|c|c|c|c|c|c|c|c|}
\hline \multicolumn{2}{|c|}{ Alternative condition } & $\begin{array}{l}\text { Manual } \\
\text { opera- } \\
\text { tion: } \\
\text { Stand- } \\
\text { ard. }\end{array}$ & $\begin{array}{l}\text { OPCON } \\
\text { opera- } \\
\text { tion: } \\
\text { Stand- } \\
\text { ard. }\end{array}$ & $\begin{array}{l}\text { OPCON } \\
\text { opera- } \\
\text { tion: } \\
\text { Incre- } \\
\text { ased } \\
\text { steam } \\
\text { flow. }\end{array}$ & $\begin{array}{l}\text { OPCON } \\
\text { opera- } \\
\text { tion: } \\
\text { Decre- } \\
\text { ased } \\
\text { steam } \\
\text { flow. }\end{array}$ & $\begin{array}{l}\text { OPCON } \\
\text { opera- } \\
\text { tion: } \\
\text { Repro- } \\
\text { ducing } \\
\text { test of } \\
\text { Exp.-1. }\end{array}$ & $\begin{array}{l}\text { Manual } \\
\text { opera- } \\
\text { tion: } \\
\text { Stand- } \\
\text { ard }\end{array}$ & $\begin{array}{l}\text { OPCON } \\
\text { opera- } \\
\text { tion: } \\
\text { Full } \\
\text { auto- } \\
\text { matic. }\end{array}$ & $\begin{array}{l}\text { Manual } \\
\text { opera- } \\
\text { tion at } \\
\text { optimum } \\
\text { point of } \\
\text { Exp.-5. }\end{array}$ \\
\hline \multicolumn{2}{|c|}{ Experiment number } & - & 1 & 2 & 3 & 4 & - & 5 & 6 \\
\hline Naphtha & $\mathrm{L} / \mathrm{hr}$ & 995 & 978 & 941 & 939 & 976 & 410 & 422 & 431 \\
\hline Fuel gas & $\mathrm{N}$ cu.M/hr & 448 & 590 & 559 & 664 & 505 & 187 & 201 & 201 \\
\hline Oxygen & $\mathrm{N}$ cu.M/hr & 468 & 481 & 486 & 470 & 468 & 196 & 192 & 191 \\
\hline Steam & $\mathrm{Kg} / \mathrm{hr}$ & 917 & 919 & 997 & 773 & 925 & 366 & 398 & 396 \\
\hline $\begin{array}{l}\text { Preheated } \\
\text { temperature } \\
\text { of naphtha }\end{array}$ & $\operatorname{deg} . \mathrm{C}$ & 500 & 510 & 510 & 510 & 500 & 500 & 515 & 520 \\
\hline Cracked gas & $\mathrm{N}$ cu.M/hr & 1,474 & 1,614 & 1,557 & 1,661 & 1,503 & 608 & 604 & 614 \\
\hline \multicolumn{10}{|c|}{ Main component of the cracked gas } \\
\hline $\mathrm{CO}$ & vol. $e^{x}$ & 16.5 & 17.8 & 16.0 & 18.8 & 16.2 & 12.3 & 12.2 & 12.9 \\
\hline $\mathrm{CH}_{4}$ & vol. "s & 10.0 & 9.8 & 9.7 & 9.5 & 10.4 & 11.5 & 12.3 & 13.6 \\
\hline $\mathrm{CO}_{2}$ & vol. & 21.0 & 20.3 & 21.3 & 18.7 & 20.2 & 22.0 & 23.3 & 22.8 \\
\hline $\mathrm{C}_{2} \mathrm{H}_{2}$ & vol. 9 & 9.6 & 9.0 & 9.2 & 9.0 & 8.9 & 10.9 & 9.9 & 9.7 \\
\hline $\mathrm{C}_{2} \mathrm{H}_{4}$ & vol. , & 7.7 & 7.5 & 7.5 & 6.8 & 8.8 & 7.3 & 10.5 & 10.3 \\
\hline $\mathrm{C}_{3}$ to $\mathrm{C}_{6}$ & vol. & 1.3 & 1.2 & 1.1 & 1.1 & 1.4 & 1.6 & 1.9 & 1.9 \\
\hline $\mathrm{H}_{2}$ & vol. $c_{c}^{\prime}$ & 31.6 & 32.1 & 30.7 & 32.1 & 27.5 & 27.7 & 26.7 & 27.0 \\
\hline $\begin{array}{l}\text { Yield }^{-} \\
\qquad\left(\mathrm{C}_{2} \mathrm{H}_{2}+\mathrm{C}_{2} \mathrm{H}_{4}\right)\end{array}$ & wt. & 46.4 & 49.4 & 50.0 & 50.3 & 49.7 & 49.0 & 53.4 & 51.9 \\
\hline $\mathrm{C}_{2} \mathrm{H}_{4} / \mathrm{C}_{2} \mathrm{H}_{2}$ & $\mathrm{Kg} / \mathrm{Kg}$ & 0.86 & 0.89 & 0.88 & 0.81 & 1.06 & 0.72 & 1.14 & 1.14 \\
\hline \multicolumn{10}{|c|}{ Material requirements } \\
\hline Naphtha & $\mathrm{Kg} / \mathrm{Kg}-\mathrm{C}_{2}{ }^{\prime \prime+\prime \prime \prime}$ & 2.15 & 2.02 & 2.00 & 1.99 & 2.01 & 2.04 & 1.87 & 1.93 \\
\hline Oxygen & $\mathrm{Kg} / \mathrm{Kg}$ & 2.18 & 2.15 & 2.23 & 2.14 & 2.08 & 2.12 & 1.84 & 1.85 \\
\hline Steam & $\mathrm{Kg} / \mathrm{Kg}$ & 2.99 & 2.87 & 3.20 & 2.46 & 2.88 & 2.77 & 2.67 & 2.39 \\
\hline Fuel gas & $\mathrm{N}$ cu.M/hr & 1.46 & 1.84 & 1.80 & 2.12 & 1.57 & 1.42 & 1.35 & 1.21 \\
\hline Fuel/Oxygen 1 & Neu.M/Neu.M & 0.96 & 1.23 & 1.15 & 1.41 & 1.08 & 0.95 & 1.05 & 1.05 \\
\hline
\end{tabular}

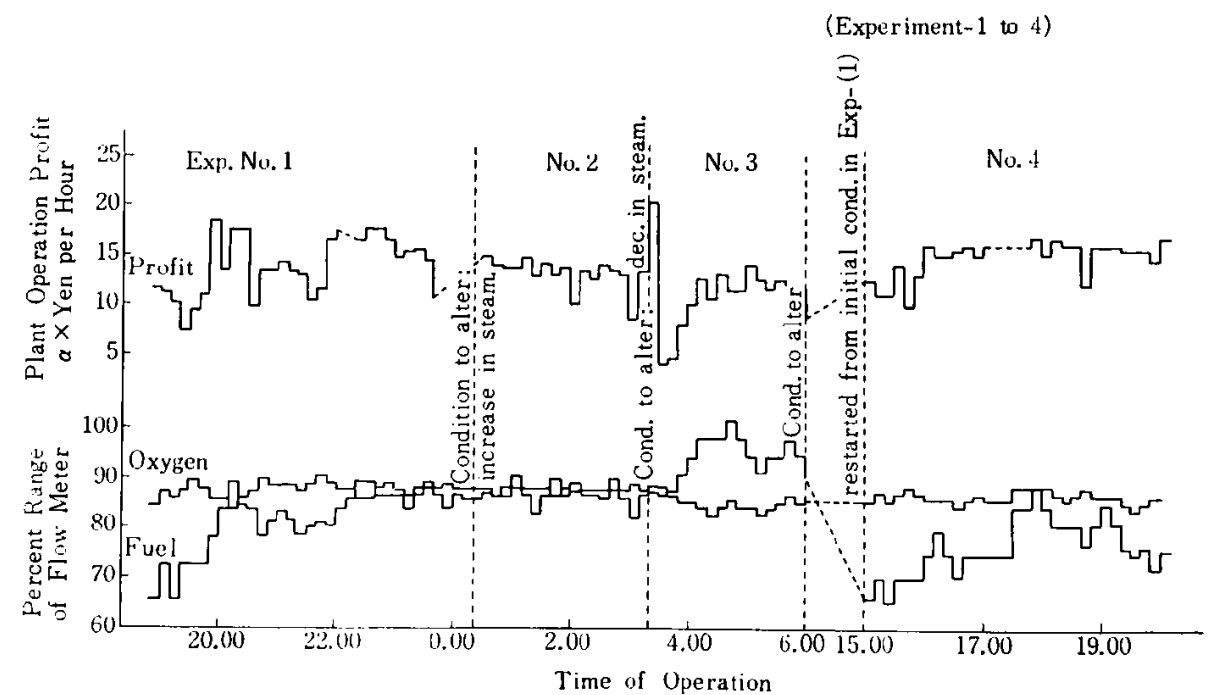

lig. 3 Change in oxygen and fuel flow, and plant operation profit with lapse of time. 


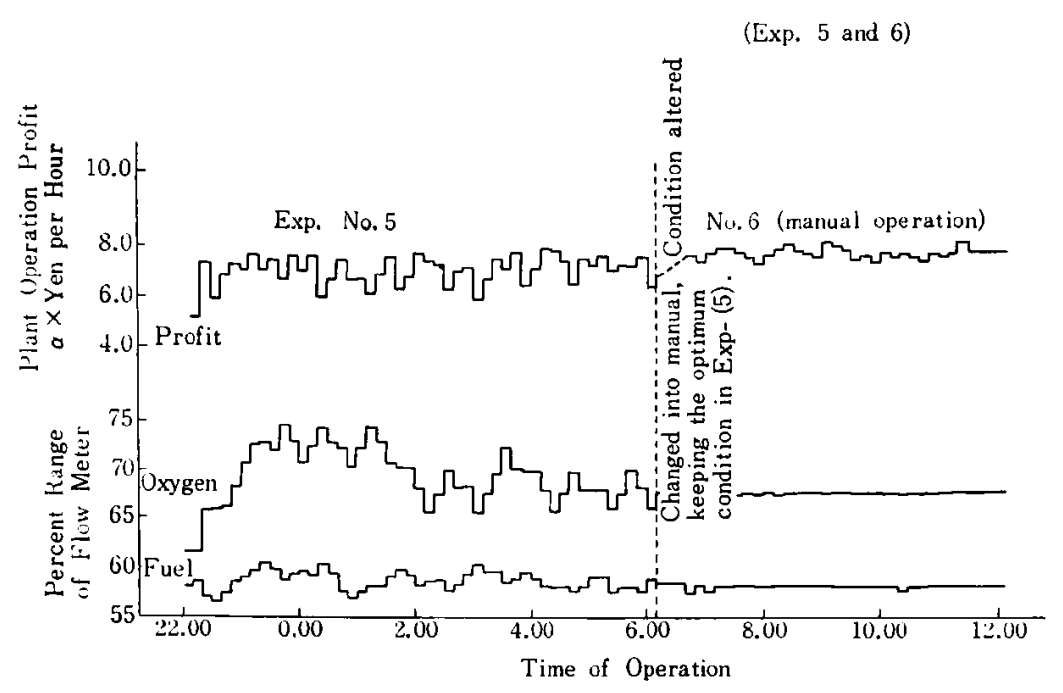

Fig. 4 Change in oxygen and fuel flow, and plant operation profit with lapse of time.

should not be regarded as the highest and only condition for that furnace.

\section{Discussion}

\section{Adoption of OPCON}

\section{Stability of Process}

In naphtha cracking furnace, it has been noted from the experimental results that acetylene and ethylene concentrations were scattered about. This is partly due to defects inherent to the apparatus, but largely due to the process-related factors, independent upon the mechanical structure of the apparatus. Be that as it may, it is important to stabilize the process as far as possible, as a pilot plant and also from the situation of a commercial plant.

Factors Affecting Concentration of Acetylene and Ethylene.

1) Reaction Temperature: From the equilibrium relationship between acetylene and ethylene, to keep the constant temperature is important. However, the following difficulties are encountered in measuring the reaction temperature. (a) Since there exists a wide temperature distribution in the reaction zone, no single point really represents the reaction temperature. This is experimentally known from the relationship between temperatures at various points in the furnace and the composition of the cracked gas. (b) Carbon deposits on the wall of protecting tube of the thermo-well, which makes it difficult to correctly measure temperatures.

2) Composition of Combustion Gas:
The combustion gas will be mixed directly with naphtha, thus affecting the reaction, which effect is also acknowledged by experiment.

\section{Fuel Gas}

From the above discussion, the flow and composition of the fuel appreciably influence the reaction. However, in the case with the commercial plants, it is difficult to provide fuel of constant composition. Even if it is technically possible, it may not be economically feasible. In this pilot plant, the composition of the fuel gas was not kept constant the effect of which was clearly noticed.

\section{Orygen}

Oxygen is available at purity high enough for practical purposes. Therefore, the oxygen composition does not create any problem. However, the oxygen flow rate greatly affects the reaction. It is so sensitive to the reaction that measurement errors due to variation in atmospheric temperatures can not be ignored.

\section{Yield of Acetylene and Ethylene}

Especially in this process, the yield of the objective products or acetylene and ethylene has a significant bearing on the process economics.

\section{Purpose for Using OPCON}

OPCON was used for the following purposes :

1) To obtain the most economical operating conditions to run the pilot plant: To let the OPCON search out the optimum point with the purpose of improving the efficiency 
of experiment. This is one of the best applications of the optimizing control by trialerror method.

2) To appraise the computor control as applied to a commercial plant: In this process, the reaction temperature and composition of the fuel gas are quite important. However, these are difficult to measure directly, thereby making it necessary to develop an alternative control method, for which the following two methods are proposed; (a) To measure the composition of the fuel: With this, the theoretical requirements for oxygen and the fuel are to be calculated to set each flow. (b) To operate optimized control by trial-error method: The result thus obtained should satisfy the above requirement.

3) Comparison of the two methods: With (a) method, required expenses will be high for the detection of the fuel gas component alone, and moreover, troublesome calculation will be required. Further, it is not optimizing control up to this stage, and that it will also require computor control of large scale by using digital computor, for a complete control. On the other hand, in case (b), all that is necessary is nearly the same expenses required for analysis of fuel component. Also, this process is relatively suitable for application of trialerror method, namely; (a) The number of process variable is two. If steam is added, the number will become only three. (b) Because of a quick process response, a shorter sampling interval can be possible. (c) Having one peak, the configuration of the mountain of the plant operation profit is simple. As a result of the foregoing analyses, the adoption of OPCON was judged appropriate.

Estimation on Contour Line of the Profit

A contour line of profit was estimated for each of the Experiment 1 thru 4. The estimation was made as outlined below. E, A, and $\mathrm{G}$ were presented as functions of $x_{2}$ and $x_{: ;}$from the measured values, and were expressed in a surface of the second order as shown by the Equation-3. Coefficients were obtained by the least square method, and the approximation was nearly satisfactory in the quadratic form.

$$
E=k_{1}+k_{2} x_{2}+k_{3} x_{2}{ }^{2}+k_{4} x_{3}+k_{5} x_{3}{ }^{2}+k_{6} x_{2} x_{3} \ldots \text { (3) }
$$

Similar equation were obtained for $\mathrm{A}$ and G. Variables other than the above-mentioned three do not change appreciably and have little effect on the profit, if purposely changed as parameter, thus making it possible to ignore them for our present purposes. Thus, the profit $\pi$ can be expressed in a mathematical model as the function of $x_{2}$ and $x_{3}$, or the flow of oxygen and fuel respectively, for each of the experiments. An example is shown in Fig. 5 in which the contour line

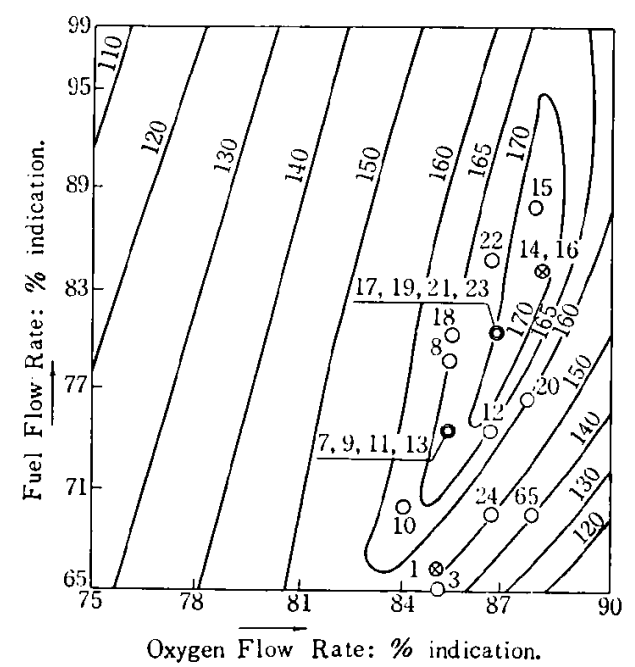

Fig. 5 Locus drawn by the OPCON

obtained from mathematical model and the locus drawn by the OPCON are illustrated for the Experiment-4. It can be roughly stated that the OPCON climbed up a mountain although it did not entirely reach the peak. However, the failure to reach the summit should not be ascribed to weakness of OPCON, but rather to a departure of the mathematical model from the actual.

That is ; there will be a deviation of approximately \pm 5 percent for the height of the mountain peak of the mathematical model, for reason that the measured data are rather scattered and that the number of plot is limited. Provided that due considerations are given to the above, it can be said that the OPCON finds the optimum point.

\section{Sampling Time Interval of the OPCON}

Reaction in this process is very quick, and the time lag between the input and output of the reaction furnace is believed to be less than a second. The time lag in this reaction system is controlled chiefly by analytical instruments. Namely, the time will be delayed by approximately one minute for the sampling system, assuming there is no gas mixing. According to the actual result, the time wasted was approximately 50 seconds, and approximately 100 seconds were neces- 
sary before the system goes back to a complete equilibrium.

Further, the process gas chromatograph requires approximately 2.5 minutes to write one bar-graph for each of acetylene and ethylene. After eye-reading of the recorded graph, approximately one minute allowance is required to manually set the potentiometer of the analog computor. On the other hand, sampling interval of the gas chromatograph was 10 minutes at the beginning, which was reduced down to five minutes. With all of the above in mind, the interval of the OPCON was set at 10 minutes, twice as long is that of gas chromatograph.

\section{Step-Width of the OPCON}

As for the ratio of step-width of oxygen to fuel, it can be estimated from the past results, since each is set so as to give approximately the same effect on the profit. An accurate estimation of the absolute value of the width was impossible because of scarcity of data.

Under the circumstances, a measure was taken so that correction be made after operating the OPCON. In the first trial, this was set at 3 percent for oxygen and at 8 percent for fuel, as the step-width of the OPCON, in terms of percent of the indicated value of the instruments. Halfway in the Experiment-1, it was changed to 2 percent for oxygen and 4 percent for fuel, which gave a satisfactory result, as a whole. In the Experiment-5, since it is designed to maintain the optimum condition, the stepwidth was further minimized to 1 percent for oxygen and 3 percent for fuel. In this experiment, change in the profit was somewhat larger as compared with that in case of manual operation, and it is presumed that the step might be still greater.

\section{Experiments Made for Changed Parameter}

Experiment-1, 2 and 3 are the ones in which the parameters were changed, and for each experiment the conditions are believed to have approached the optimum point. The conditions finally obtained are shown in Table 2, indicating favorable results in every case such as high yield of $\mathrm{C}_{2}$ fraction and minimum requirements of raw material and supplies.

\footnotetext{
Reproducibility of OPCON for optimum Operation

Comparing Experiment-1 against Experi-
}

ment-4, both with the same values in the operating profit, a difference in the optimum point is noticed. From this fact, it is presumed that the OPCON will seek an optimum point at that state of operation, acting against the disturbances from the outside during the operation of the process. As shown in Fig. 5 indicating the locus of the OPCON, it can be also presumed that the mountain of the optimum condition of this process is long and slender in its configuration and that the optimum point is apt to move along the peak line of the mountain.

Comparison of Operation between OPCON and Manual Control

The comparison was made in the Experiment-5 and 6. As shown in the Fig. 4, indicating its changing trend in the profit, there can be seen a greater variation in the OPCON control operation than that of manual operation. When the averaged profit is compared between the two after the optimum condition has been searched out, the case of manual operation is greater than the case of the OPCON by approximately 1.1 times. The result is understood natural because the manual operation was made, repeating trial, on tap of the optimum condition which OPCON had searched out. From the result obtained above, within the range of a short time such as this experiment was made, it was made clear that the position of the mountain of profit scarsely moved because of slight variation caused by the outside disturbances. This appears to conflict with the result of discussion previously made for the comparison of reproducibility, but this is believed to come from a difference in size of the furnace between the cases in Experiment1 to 4 and the cases in Experiment-5 and 6, and consequently from a difference in the capacity to be treated per unit volume of the furnaces. The outside disturbances, related with the structure of the furnace and the instruments, can be eliminated by improving their individual defects. It will be of advantageous to utilize OPCON against such outside disturbances as changes in the atmospheric temperature.

\section{Major Improvement of OPCON}

(1) Separation of analog computor section from OPCON section: It will be beneficial to separate the analog computor from OPCON. since analog computor has a greater possibility for wide variation to meet the process. 
(2) The logic to be applied for the trial-anderror method in the OPCON is better changed, in accordance with the purpose for using the OPCON. For instance, there will be a difference in the logic to be applied between the two cases, one is the case to search for optimum point and another is the case in which the movement on optimum point is to be pursued. (3) Alarm device for the restricted condition: There may be two choices for alarm, one is the case this device is included in the OPCON, while another is the case this device is attached outside. Any how, it will be beneficial, at least, that an alarm device is to be included in the OPCON so that any upper or lower limits can be optionally set for the output variable of the OPCON.

\section{Investigation on the Optimum Data Obtained by the OPCON}

In the foregoing, focus of the discussion has been placed on the action of the OPCON. In this item, authors wish to investigate, by making comparison of the optimum data which OPCON has finally worked out.

Regarding the Experiment-1 and Experiment-5, when these two are compared with the reference data manually operated without using OPCON, it is recognized that OPCON raised the yield and minimized requirements for the raw material and utilities, thus proving the advantage of the OPCON operation in every case. In case where the steam flow was changed, as shown in the data of Experiment-1, 2 and 3, only slight variations in the yield and in the requirements for material and utility are seen, and comparatively satisfactory results were obtained. In the OPCON operation, in every case, final condition for the fuel/oxygen ratio was always set at a condition whereby the fuel is in surplus over the theoretical amount. This means that the conversion of the raw material naphtha into carbonmonoxide or carbondioxide is restricted and that OPCON is searching for raised yield of $\mathrm{C}_{2}$ fraction. Therefore, it can be said the OPCON is searching a favorable tendency, in view of this reaction. As compared with Experiment-1 to 4 against Experiment-5 and 6, both of which were similarly operated by OPCON, the latter, Experiment-5 and 6, showed better results in the yield and in the requirements for raw material and utilities. This is believed to come from the difference in furnace capacity, per unit volume of the furnace, and that there appeared an effect coming from the structure of the furnace. Viewed from these points, the optimum condition which OPCON has sought out can not be said as the highest condition of the furnace. Further, it becomes necessary to search for conditions which will bring maximum profit for each parameter, by changing the condition of the process parameter, or, by changing the selection of the output variables. After that, the maximum profit for each parameter is to be investigated to find the condition which will bring about an over-all maximum profit. Such a problem may be the one to be discussed rather with the commercialized plant. For such a purpose, the OPCON has big advantages because it is helpfull in computing the data within a short time.

\section{Conclusion}

In the foregoing, a report was presented on the results of the automatic operation of naphtha cracking furnace by optimizing controller applying a trial-and-error method. It was made clear that the optimizing controller is effective in searching for the optimum operating condition.

The number of output variable of the OPCON used in this experiment was two. However, an increase in number gives better results. At the present stage, a highest furnace condition is obtainable from various optimum points corresponding to changed parameter of the operating conditions, thus improving the efficiency of the experiment. This OPCON is useful in case where the disturbances on the process come from outside such as the structural effect of the furnace, and also, in case of disturbances from changes in weather, etc. Where there are only slight outside disturbances; for instance, in case of a furnace creating less disturbances, investigation will become necessary for step of control, etc. From results of the experiment carried out both by automatic and manual control, it was naturally confirmed that this was a stabilized process, freed from outside disturbances, if an appropriate capacity is used.

It was also made clear, for the cracking furnace used in this experiment, that the plant operation profit is not affected so much by the operating condition, at condition of $\mathrm{E} / \mathrm{A}=1$, or, therearound.

In this control instrument, the input from the analytical instruments was not made automatically, and also there are some points 
which should be improved, but these problems are not difficult to solve technically. Therefore, it appears feasible, in case of a commercial plant, a cracking furnace can be operated fully automatically, using instruments which allow for more input and output variables.

This experiment has been carried out through cooperation of many participants from Kureha Chemical Company, Mitsubishi Electric Company and Chiyoda Chemical Engineering and Construction Company, to whom thanks and acknowledgements are given by the authors.

\section{References}

1) Akin, G. A., Reid, T. F., and Schrader, R. J., Chem. Eng. Prog., 54, (1), 41 (1958).

2) Patton, J. L., Grubb, G. C., and Stephenson K. F,. Petrol. Refiner 37, (11), 180 (1958).

3) Krekeler, H., Wirtz, R., and Pechtold, N., Fifth World Petrol Congress Report. Sec. IV, Paper 5 (1959).

4) Matsumoto, T., Electoronic Engineering 4, (4), 113 118 (1962).

5) Soderquist, F. J., Chem. Eng. Prog., 57, (9) 40 (1961). 